Finalizando, o que se pode dizer ë que Raúl Prebisch consegue com relativa maestria elaborar uma análise introdutória da Teoria Gerăl de Keynes, tendo como mérito principal a clarividência em estabelecer pontos de ligação entre uma obra de reconhecido fôlego dentro da Teoria Econômica e a realidade das economias em desenvolvimento, fazendo uso inclusive de fatos históricos com intuito ilustrativo do grau de adequação das proposições de Keynes para as economias capitalistas. Há que se ressaltar que o presente trabalho de Raúl Prebisch deve ser visto como um referencial ímpar para a divulgação das origens da economia keynesiana de uma maneira adequada aos leitores que necessitam dos conhecimentos básicos do pensamento econômico. $\square$

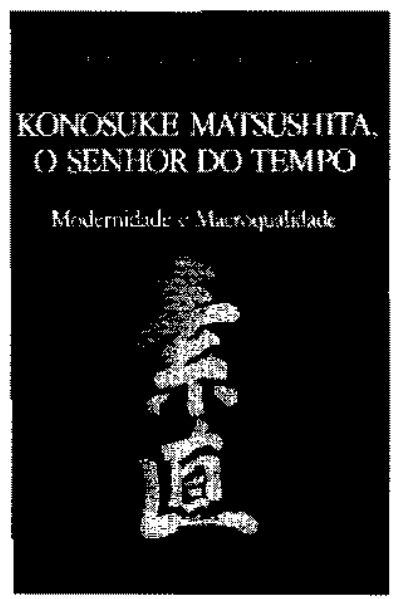

\section{KONOSUKE MATSUSHITA, O SENHOR DO TEMPO - MODERNIDADE E MACROQUALIDADE}

\section{de LUIZ FERNANDO DA SILVA PINTO}

São Paulo: T. A. Queiroz, 1992.

Por José Cezar Castanhar, Diretor Administrativo da FGV e Professor da EBAP/FGV.

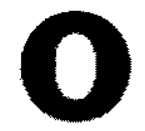

$s$ recentes reveses sofridos pela economia japonesa (declínio da lucratividade das empresas, crise no mercado financeiro e queda nas taxas de crescimento econômico) têm feito ressurgir previsões pessimistas, muitas vezes apocalípticas, sobre o futuro da economia e da sociedade japonesas. $\hat{E}$ comum oungirem, nesse contexto, minuciosas análises vaticinando o próximo e inexorável ocaso do ímpério pais do sol nascen- te. Na realidade, nos ültimos 20 anos insuspeitos analistas têm realizado previsöes semelhantes. Foi assim em 1973 e 1978 por ocasião dos dois choques do petróleo, na recessão econômica dos países desenvolvidos entre 1979 e 1982 e, finalmente, com a queda do dólar e a espetacular valorização do yen entre 1985 e 1987.

Em todas essas ocasiōes afirmaram os analistas internacionais que o Japão, sendo uma economia profundamente dependente de matérias-primas (especialmente o petróleo) para ofuncionamento de suas indústrias e do comércio internacional para o escoamento de sua produção, seria mortalmente atingido em sua vitalidade econômica e dificilmente se recuperaria. Em todas essas ocasiões, todavia, a economia japonesa frustrou a expectativa daqueles que anteciparam o seu ocaso e emergiu das crises mais sólida e vigorosamente.

De fato, em todos aqueles momentos, o Japäo enfrentou crises formidáveis que poderiam ter levado qualquer outra sociedade à estagnação e decadência, o que realmente ocorreu, tanto em paises muito ricos como em outros, nem tanto. A economia japonesa soube encontrar, no entanto, a dose certa de disciplina, tenacidade, inovação e entusiasmo para superar adversidades e prosseguir na sua trajetória de crescimento, consolidando cada vez mais sua vitalidade e ampliando, na realidade, sua liderança mundial.

E agora? Chegou, finalmente, a hora da verdade para o Japão? Será a crise atual aquela que a economia japonesa não encontrará forças e meios para superar? Uma atitude prudente dos analistas internacionais antes de responderem a essas perguntas seria indagar antes: o que é, na verdade, o Japão?; cor mo funciona a economia japonesa?; como pensa e reage o empresário japonês em face da crise?. Nessa tarefa, o livro Konosuke Matsushita, o Senhor do Tempo - Modernidade e Macroqualidade, de Luiz Femando da Silva Pinto, pode ser um importante e insubstituível guia. Indicado a professores e executivos interessados em técnicas gerenciais japonesas, tratase de uma formidável e minuciosa análise da formação do caráter, das habilidades artesanais e estratégicas e da sensibilidade social do empresário e da sociedade japonesa em geral, partindo de um estudo biográfico preciso e penetrante de um de seus mais talentosos e bem-sucedidos representantes: Konosuke Matsushita, fundador da Corporação Matsushita, mundialmente conhecida por suas marcas National, Panasonic, Technics e Quasar.

Partindo de um pequeno empreendimento artesanal na cidade de Osaka em 1918, Konosuke Matsushita construiu um império empresarial que opera hoje em uma centena de países, ostenta um fatura- 
mento anual da ordem de US $\$ 50$ bilhōes emprega mais de 130.000 pessoas em todo o mundo. Segundo Luiz Fernando da Silva Pinto trata-se, certamente, de um dos mais importantes e inovadores empreendedores deste século. É importante ressaltar, desde já, que não se trata de mais um livro sobre o sucesso empresarial japonês. Pela profundidade da pesquisa empreendida, pelo rigor analítico e pela riqueza da metologia utilizada, pode-se afirmar que a obra de Luiz Fernando da Silva Pinto é o livro sobre o Japão. $O$ que o distingue dos demais é a discussão admiravelmente profunda e consistente de aspectos cruciais da cultura e da ética empresarial japonesas a $_{t}$ aspectos que têm sido negligenciados na maioria das obras sobre o tema, sejam técnicas ou biográficas.

Uma das mais importantes e originais contribuições do livro é o trabalho minucioso de pesquisar e delimitar a moldura cultural, dentro da qual se iräo definir os principais atributos da empresa, do empresário e do trabalhador japonês. Conforme assinala Luis Fernando, o Japão, ao enfrentar um desafio, seja estratégico, tático ou físico, não escolhe o melhor caminho. Ao invés de escolher, ele constrói o melhor caminho. Em japonês, caminho traduz-se por $D \hat{O}$, palavra que apresenta densidade filosófica e cultural praticamente sem limites. $O$ autor denomina esse "caminho construído" de ESPACO DÔ, o qual, por seu turno, é delimitado por três planos (no sentido geométrico) mestres.

O primeiro Plano Mestre que entra na construção do ESPACO-DO é denominado de NIPPON-TO, expressão que significa espada japonesa e que é usada pelo autor para retratar "somatório e agregação de valores bem definidos", acrescido de preocupação estética, bem como "simbolismos e posicionamentos formais relativos à sua utilização". $O$ NIPPON-TO é, portanto, o plano que delimita a integração de todo um elenco de valores culturais japoneses, distinguindo-se, dentre outros, os seguintes:

- o sentido de família e a propensão à integração;

- a propensäo à absorção de valores culturais externos;

- a propensão ao manejo global, regulamentado por grandes códigos;

- o sentido da legitimação;

- as heranças religiosas;

- as heranças de segmentação da sociedade feudal;

- o sentido de dever e obrigaçóes recíprocas;

- a necessidade de comando;

- a senioridade como fator organizacional;

- as sutis escalas do tempo;

- o disciplinamento da inimizade;
- a aversão ao risco:

- o sentido de missão e de dever cumprido etc.

Se o plano NIPPON-TÔ reflete os valores culturais japoneses e suas inter-relaçōes, o plano seguinte retrata atributos $\mathrm{e}$ habilidades físicas $\mathrm{e}$ intelectuais da sociedade japonesa. Esse plano, denominado pe-

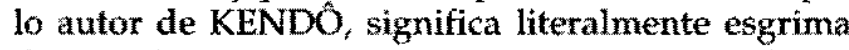
de espadas japonesas, uma arte marcial moderna mas com raízes ancestrais. Cabe notar que esses atributos e habilidades foram construídos lentamente, ao longo de praticamente mil anos de história, incluem aspectos como: Força, Agilidade, Intuição, Velocidade, Equilíbrio, Determinação, Coragem, Adestramento e Eterna Disposição, entre outros fatores.

O terceiro Plano-Mestre é denominado WA, expressão que em japonês significa harmonia. Observa o autor que esse é o conceito mandatório de todo o processo de ação do país, seja cultural, artístico, econômico, social, financeiro, filosófico-institucional ou geopolítico. Assim, o plano WA completa a construção do ESPACO-DÔ delimitando uma região onde a harmonia condiciona qualquer empreendimento. " $E$ como se nessa regiño todos assinassem um contrato implícito para a manutencâo da harmonia ao longo de todo um processo bem definido de açấo."

O ESPACO-DÓ, assim constituido, representa a região na qual a sociedade japonesa busca inspiração, força e orientação para criar suas soluçöes. Segundo o autor, o ESPAÇO-DÔ poderá ser percorrido por artistas, intelectuais, políticos, governantes $e$ empresários. No caso empresarial, o deslocamento ao longo do ESPAÇO-DÔ será facilitado pela capacidade de agregaçăo corporativa e coesão verificada entre os vários segmentos de um mesmo complexo empresarial e entre este e a comunidade que o circunda (local ou nacional).

Fica evidente, por outro lado, através da rica análise empreendida pelo autor, que as constantes tentativas de importar as denominadas "artes gerenciais japonesas", na ausência de um exame cuidadoso do contexto sócio-cultural e das adaptações necessárias, só serão bem-sucedidas por mero acaso.

Observa-se, assim, que o talento japonês em superar crises reflete muito mais do que uma peculiar competência gerencial. De fato, ele parece ser fruto de uma estratégia coletiva profundamente vinculada à cultura do país. Essa estratégia caracteriza-se pela construção harmônica dos caminhos necessários ao alcance do progresso e do bem-estar da sociedade. Nesse esforço, identificar os possivieis riscos e agir de forma a evitá-los, constitui-se na principal prioridade. Assim, quando surge uma crise, o país revela-se mais preparado do que qualquer ou- 
tro para enfrentá-la e superá-la. Um exemplo espetacular dessa obsessão em evitar riscos é descrito pelo autor ao mencionar que em 5 de maio de 1932, quatorze anos após a sua fundação, a Matsushita implantou o que fó denominado de "revolução da missão corporativa" ou "Dia de Meichi". Esse compromisso compreendia o estabelecimento de um planejamento abrangendo um prazo de 250 anos que seria enfrentado em 10 estágios de 25 anos cada um. Em 5 de maio de 1982, a direção mundial da empresa comemorava o início do terceiro módulo desse planejamento.

No exame das características culturais que constituem a inspiração das açöes e fonte dos talentos do empresário japonês, Luiz Fernando da Silva Pinto chama a atenção para uma que pode parecer particularmente desconcertante para o observador ocidental: trata-se da peculiar relação entre a empresa e a sociedade naquele país. Na visão de Konosuke Matsushita uma empresa e a sociedade que a recebe são sócios, na realidade mais do que isso, săo "cúmplices ${ }^{z}$ de um mesmo empreendimento. Compreender as sutilezas dessa visäo é indispensável para entender algumas das mais marcantes características da empresa e da economia japonesas em geral, tais como a preocupação primordial com o consumidor. a ênfase na qualidade total, a estabilidade nos contratos de trabalho, dentre outras.

O autor seleciona algumas "máximas" cunhadas por Matsushita e que refletem bem o espírito dessa parceria empresa/comunidade/trabalhador:

- uma empresa é algo que a sociedade nos confia;

- progredir em harmonia com a sociedade;

- o lucro não é a nossa finalidade, mas a nossa recompensa;

- em primeiro lugar o consumidor;

- um déficit ẻ um delito;

- uma empresa é o seu pessoal;

- formar seu pessoal antes de fabricar produtos;

- renascer a cada dia.

Esse credo empresarial sempre adquiriu contornos práticos e operacionais na Matsushita. Assim, por exemplo, no que toca ao Controle de Qualidade, tema que hoje monopoliza o interesse e a atenção de empresários e governos em todo o mundo, é impressionante constatar que em outubro de $1942 \mathrm{Ko}-$ nosuke Matsushita promulgava os "7 artigos" que deveriam nortear a preocupação da empresa com a qualidade. $O$ primeiro desses artigos estabelecia que "continuaremos a enfatizar a nossa crença básica em satisfazer o consumidor formecendo-lite um produto merece- dor de cuidados, encantos, decencia e perspectioa de agrado". No quinto artigo se dizia que "tentaremos honrar a nossa marca National" pelo próprio ato de apresentar ao público um produto sem defeitos". Ainda em 1946 Konosuke Matsushita fundava o Quality Assurance Laboratory, atuando ele proprio como seu diretor.

Atenção especial ê dedicada pelo autor ao estudo da delicada integração entre a empresa e a comunidade. Um dos grandes talentos de Matsushita foi, nesse sentido, utilizar as "alavancagens comunitárias ${ }^{\prime \prime}$ potencialmente existentes na sociedade japonesa e amplificadas pela sua peculiar herança cultural. Segundo Luiz Fernando, Matsushita desenvolveu máquinas comunitárias de ação empresarial onde a competição e a inovação fazem parte do combate de cada dia, "só que esta 'máquina empresarial' preserva o direito de seus colaboradores, revendedores $e$ consumidores, como se todos fossem parte de um tínico 'corpo de ação'. Eles também sabem ser agressioos, duros e implacáveis na perseguiçäo de objetivos empresariais, vencendo imensos sacrifícios no seu desafio. O efei-" to comunitário não abranda o apetite para a luta. Ao contrário, estimula-o, com a participação de todos".

Luiz Fernando Silva Pinto conclui sua profunda e reveladora análise afirmando que não existe uma síntese possível para o mundo de Konosuke Matsushita, tal a amplitude e profundidade de suas ações, de seus pensamentos e de sua visão universal. De um lado empresário altivo e orgulhoso de sua condição. De outro, procurou com notáyel humildade definir papéis e responsabilidades para a atuação empresarial que transcenderam a simples esfera de segurança no binômio investimentos/lucros compensatórios.

Já nonagenário, Matsushita preocupava-se seriamente com o próximo século, uma vez que o futuro imediato já estaria equacionado pelos avanços técnico-científicos alcançados pela sociedade mundial. Nesse quadro, o tempo é apenas mais uma variável de trabalho. "Nesta visão dinâmica, a RENOVAÇÃO seria uma conveniente busca da modernidade". E o que seria modernidade? Para Matsushita, basicamente um estado de comprometimento com o processo de vanguarda científica e tecnológica, objetivando-se sempre a melhoria do bem-estar social e da qualidade de vida da sociedade como um todo, com novos laços de solidarização e alavancagem comunitária.

Concluindo, um lembrete de Konosuke Matsushita particularmente oportuno para o atual momento da sociedade brasileira: "Existirá sempre uma moldura ética $e$ moral cercando as atividades setoriais de um sistema empresarial. Identificar tal moldura, e desenvolver-se dentro de seus limites, é tarefa imprescindivel e inarredável em qualquer filosofia de aça empresarial". 
tro para enfrentá-la e superá-la. Um exemplo espetacular dessa obsessão em evitar riscos é descrito pelo autor ao mencionar que em 5 de maio de 1932 , quatorze anos após a sua fundação, a Matsushita implantou o que foi denominado de "revolução da missão corporativa" ou "Dla de Meichi". Esse compromisso compreendia o estabelecimento de um planejamento abrangendo um prazo de 250 anos que seria enfrentado em 10 estágios de 25 anos cada um. Em 5 de maio de 1982, a direção mundial da empresa comemorava o início do terceiro módulo desse planejamento.

No exame das características culturais que constituem a inspiração das ações e fonte dos talentos do empresário japonês, Luiz Fernando da Silva Pinto chama a atenção para uma que pode parecer particularmente desconcertante para o observador ocidental: trata-se da peculiar relação entre a empresa e a sociedade naquele país. $\mathrm{Na}$ visão de Konosuke Matsushita uma empresa e a sociedade que a recebe são sócios, na realidade mais do que isso, são "cúmplices" de um mesmo empreendimento. Compreender as sutilezas dessa visão é indispensável para entender algumas das mais marcantes características da empresa e da economia japonesas em geral, tais como a preocupação primordial com o consumidor, a ênfase na qualidade total, a estabilidade nos contratos de trabalho, dentre outras.

O autor seleciona algumas "máximas" cunhadas por Matsushita e que refletem bem o espírito dessa parceria empresa/comunidade/trabalhador:

- uma empresa é algo que a sociedade nos confia;

- progredir em harmonia com a sociedade;

- o lucro não é a nossa finalidade, mas a nossa recompensa;

- em primeiro lugar o consumidor;

- um déficit é um delito;

- uma empresa é o seu pessoal;

- formar seu pessoal antes de fabricar produtos;

- renascer a cada día.

Esse credo empresarial sempre adquiriu contornos práticos e operacionais na Matsushita. Assim, por exemplo, no que toca ao Controle de Qualidade, tema que hoje monopoliza o interesse e a atençấo de empresấrios e governos em todo o mundo, é impressionante constatar que em outubro de $1942 \mathrm{Ko}-$ nosuke Matsushita promulgava os "7 artigos" que deveriam nortear a preocupação da empresa com a qualidade. $O$ primeiro desses artigos estabelecia que "continuaremos a enfatizar a nossa crençá básica em satisfazer o consumidor fornecendo-lhe um produto merece- dor de cuidados, encantos, decencia e perspection de agrado". No quinto artigo se dizia que "tentaremos honrar a nossa marca 'National', pelo próprio ato de apresentar ao público um produto sem defeitos". Ainda em 1946 Konosuke Matsushita fundava o Quality Assurance Laboratory, atuando ele próprio como seu diretor.

Atençấo especial é dedicada pelo autor ao estudo da delicada integração entre a empresa e a comunidade. Um dos grandes talentos de Matsushita foi, nesse sentido, utilizar as "alavancagens comunitárias" potencialmente existentes na sociedade japonesa e amplificadas pela sua peculiar herança cultural. Segundo Luiz Fernando, Matsushita desenvolveu máquinas comunitárias de ação empresarial, onde a competição e a inovação fazem parte do combate de cada dia, "só que esta "mäquina empresarial' preserva o direito de seus colaboradores, revendedores e consumidores, como se todos fossem parte de um único 'corpo de ação'. Eles tambêm sabem ser agressivos, duros e implacáveis na perseguiçấo de objetivos empresariais, vencendo imensos sacrificios no seu desafio. O efeito comunitário Näo abranda o apetite para a luta. Ao contrário, estimula-o, com a participaçâo de todos".

Luiz Fernando Silva Pinto conclui sua profunda $e$ reveladora análise afirmando que não existe uma síntese possível para o mundo de Konosuke Matsushita, tal a amplitude e profundidade de suas ações, de seus pensamentos e de sua visão universal. De um lado empresário altivo e orgulhoso de sua condição. De outro, procurou com notável humildade definir papéis e responsabilidades para a atuação empresarial que transcenderam a simples esfera de segurança no binômio investimentos/lucros compensatórios.

Já nonagenário, Matsushita preocupava-se seriamente com o próximo século, uma vez que o futuro imediato já estaria equacionado pelos avanços técnico-cientificos alcançados pela sociedade mundial. Nesse quadro, o tempo é apenas mais uma variável de trabalho. "Nesta visão dinàmica, a RENOVAÇÃO seria uma conveniente busca da modernidade ${ }^{\prime \prime}$. E o que seria modernidade? Para Matsushita, basicamente um estado de comprometimento com o processo de vanguarda científica e tecnológica, objetivando-se sempre a melhoria do bem-estar social e da qualidade de vida da sociedade como um todo, com novos laços de solidarização e alavancagem comunitária.

Concluindo, um lembrete de Konosuke Matsushita particularmente oportuno para o atual momento da sociedade brasileira: "Existirá sempre uma moldura ética $e$ moral cercando as atividades setoriais de um sistema empresarial. Identificar tal moldura, e desenwolver-se dentro de seus limites, é tarefa imprescindivel e inarredável em qualquer filosofia de ação empresarial". 